\title{
Determinants of Farmers' Perception of Climate Change: A Case Study from the Coastal Region of Bangladesh
}

\author{
Mohammed Nasir Uddin'1, Wolfgang Bokelmann², Emily Shea Dunn³ \\ ${ }^{1}$ Department of Agricultural Extension Education, Bangladesh Agricultural University (BAU), Mymensingh, Bangladesh \\ ${ }^{2}$ Division of Economic of Horticultural Production, Faculty of Agriculture and Horticulture, Humboldt University of Berlin \\ (HUB), Berlin, Germany \\ ${ }^{3}$ Department of Agribusiness, College of Food and Agriculture, United Arab Emirates University, Al Ain, United Arab Emirates \\ Email: nasirbau@gmail.com,w.bokelmann@agrar.hu-berlin.de, emishea@uaeu.ac.ae
}

How to cite this paper: Uddin, M.N., Bokelmann, W. and Dunn, E.S. (2017) Determinants of Farmers' Perception of Climate Change: A Case Study from the Coastal Region of Bangladesh. American Journal of Climate Change, 6, 151-165.

https://doi.org/10.4236/ajcc.2017.61009

Received: December 1, 2016

Accepted: March 24, 2017

Published: March 27, 2017

Copyright $\odot 2017$ by authors and Scientific Research Publishing Inc. This work is licensed under the Creative Commons Attribution International License (CC BY 4.0).

http://creativecommons.org/licenses/by/4.0/

\begin{abstract}
Socio-economic conditions of farmers, especially in the coastal region in Bangladesh, have been severely affected because of climate change. This study was focused on analyzing the farmers' perception of climate change by examining three vital issues: (1) description of the socioeconomic characteristics of farmers; (2) reporting on the perception of farmers experiences with climatic change; and (3) identification of the socio-economic factors associated with farmers' perception of climate change. The study area encompasses three villages within the coastal region (Sathkhira district) of Bangladesh, a geographic region where climate change literature has highlighted as prone to accelerated degradation. A logit model, along with weighted indexes for ranking and descriptive statistics, was used to analyze the result of 100 farmers surveyed by questionnaire. We found that the majority of the farmers (88\%) perceived changes in climatic conditions. Almost all farmers indicated increases in temperature, droughts, floods, cyclones, salinity level and decreasing rainfall over the last 20 years. The logit model explained that out of the nine factors surveyed; education, family size, farm size, family income, farming experiences and training received were significantly related and influential factors to perception of climate change. Therefore, government and non-governmental organizations are recommended to push forward with interventions, especially focusing on identified factors, in order to strengthen the farmers' capacity to battle against climate change effects.
\end{abstract}

\section{Keywords}

Determinants, Farmers, Perception, Climate Change, Coastal Region, Bangladesh 


\section{Introduction}

Bangladesh is considered as one of the most vulnerable countries in the world to climate change because of its geographical location, economic dependence on agriculture, and recurrence of natural hazards [1]. Agricultural production is severely affected by climate change especially in Bangladesh's coastal region, where a large portion of poverty stricken population resides. Sudden natural disasters such as storm surges, floods, droughts, and cyclones are associated with longterm changes in salinity due to sea level rising, landslides which alter the landscape and, in turn, bring new pest insurgence. These are a few of the climate change challenges that farmers in Bangladesh face [2].

The predicted climate variability of Bangladesh was developed by the National Adaptation Programme for Action (NAPA) in 2008, which was shown in Table 1. This data predicts a gradual change of three important climate change events that will have tremendous effects on the farming community in Bangladesh. The United Nations Framework Convention on Climate Change developed NAPA to provide adaptive processes for Least Developed Countries (LDCs) urgent and immediate needs to climate change for the most vulnerable countries, or those countries that will incur the highest cost in damages. Bangladesh encompasses most of the priority areas addressed in NAPA, with regards to agriculture, food security, coastal zones, and early warning and disaster management [3].

The coastal region of Bangladesh has been facing numerous ongoing climatic threats which have resulted in severe damage to agricultural production, while about 70 percent of its people depend on agriculture for their livelihoods [4]. The gross national income per capita for Bangladesh is $\$ 1403$, just barely breaching the lower middle-income status of the World Bank country classification. An estimated $17 \%$ of the Bangladesh's gross domestic product is dependent on the agricultural sector, while majority of the people depend on agricultural production for their incomes and food security [5].

The socio-economic conditions of the farmers in Bangladesh are some of the most vulnerable in the world to climate change. Therefore, adaptive processes to the effects of climate change are the priority for Bangladesh and crucial to build resilience into the lives of the farmers. But before adaptation, it is necessary to understand the farmers' perception of climate change. Previous literature exist

Table 1. Predicted climate variability in Bangladesh.

\begin{tabular}{cccccccc}
\hline & \multicolumn{2}{c}{ Temperature Change $\left({ }^{\circ} \mathrm{C}\right)$} & Mean & \multicolumn{2}{c}{ Rainfall Change (\%) Mean } & Sea Level Rise $(\mathrm{cm})$ \\
\cline { 2 - 7 } & Annual & DJF & JJA & Annual & DJF & JJA & \\
\hline 2030 & 1.0 & 1.1 & 0.8 & 5 & -2 & 6 & 14 \\
2050 & 1.4 & 1.6 & 1.1 & 6 & -5 & 8 & 32 \\
2100 & 2.4 & 2.7 & 1.9 & 10 & -10 & 12 & 88
\end{tabular}

Source: GOB, 2005 [3]. Note: DJF indicates December, January and February; JJA indicates June, July, and August. 
on the perception and adaptation to climate change in different vulnerable countries similar to Bangladesh, but very limited studies are available that identify the factors affecting the farmers' perception of climate change. Therefore, this study addressed a gap in the research on specific factors and entitled "Determinants of Farmers' Perception of Climate Change: A Case Study from the Coastal Region of Bangladesh". However, the specific objectives of the research included describing the farmer's socioeconomic factors, determining the farmers' perception of climate change, and identifying significant variables to determine the farmers' perception of climate change.

\section{Literature Review}

Perception is a process of receiving information and stimuli from our surroundings and converting them into psychological responsiveness [6]. Perception of climate change, as a tremendously difficult idea for the farmers, has limited boundaries as the individual's perception differs with the past and present situation [7]. Khan et al. [8] conducted a study in the coastal region of Bangladesh about farmers perception of climate variability and found that farmers who were previously engaged in fisheries are now moving to agriculture crop production. The farmers are reacting to understanding the events of climate change, especially temperature and rainfall.

Haque et al. [9] found that majority of the participants (95\%) in Bangladesh have reported that temperature during summer months has increased, while 80.2\% participants reported that the rainfall has decreased. They also perceived that climate variability was negatively affecting the agriculture, human health and livelihoods as a whole. There is a significant relationship between small-holders farmers' perception of floods and droughts and adoption of conservation practices such as zero tillage, crop rotations, application of organic fertilizers but the authors found that farmers perceiving conservation agriculture as a climate change adaptation strategy was very low [10]. More experienced farmers have perceived that climate has changed over their working lives but failed to acknowledge how to respond in a way that reduces the effects of climate change on their livelihoods.

A research study conducted by Maddison (2007) also revealed that adaptation of climate change has involved two processes, perception of climate change and then taking a decision, whether to adopt or not [11]. Gbetibouo [12] explained that farmers of the Limpopo River Basin of South Africa perceive climate change impacts as the temperature increased while rainfall has been significantly decreased. Findings also explained that extension services have influenced farmers' perception regarding weather variability, as the extension provides the information the farmers need to choose to adapt or not.

Tiwari et al. [13] showed that average temperatures have increased from $0.6^{\circ} \mathrm{C}$ to $0.98^{\circ} \mathrm{C}$ over the last 30 years and precipitation has been characterized by large inter-annual variability with substantial decrease in amount, over the last five years. The annual temperature increases have shown a trend that has followed $0.055^{\circ} \mathrm{C}>0.0455^{\circ} \mathrm{C}>0.035^{\circ} \mathrm{C}>0.02^{\circ} \mathrm{C}$ per year from Middle Mountain, Siwlik, 
Himalayan and Teari regions, respectively. More than $80 \%$ of households surveyed responded perceived increased temperature and low amounts of snowfall in high mountains areas, and rainfall in mid mountain and Terai region, over the last five years.

\section{Research Methodology}

The study was carried out in three villages, within the coastal region of Bangladesh. This area was selected because it is prone to frequent natural hazards such as floods and cyclones. Face to face interviews were conducted with 100 farmers in May 2012 using structured questionnaire with both open and closed questions. Logistic regression, weighted indexes, and descriptive statistics were used to analyze the farmers' responses to the questionnaire.

Perception is measured by a dummy variable in the model which was assigned a value of 1 for farmers' who perceived climate change and a value of 0 for farmers who did not perceive climate change events. It indicated that the probability of an individual with a given set of attributes will fall in one choice (perceive) rather than the alternative (or not) but not both. Climate change events were defined in the questionnaire as increased or decreased temperature, rainfall, drought, flood, salinity, etc.

A logistic regression model was selected to identify the significant variables that determined whether farmers were perceptive of climate change, or not. The data could have been analyzed by different probability models where the dependent variable is a dummy. The models that were considered include the Linear Probability Model (LPM), logit model and probit model. Justification of the logit model was based on the following drawbacks of the LPM and probit model.

The LPM showed the uniformity of error terms and possibility of getting the probability function result out of 0 and 1 . Due to this problem LPM is not logically attractive model for dummy responsive variables. It is better to use Cumulative Distribution Function (CDF) namely logit or probit models when analyzing this type of questionnaire [14]. The probit model is suited to experimental data while logit model is for observational data [15]. The data collected was categorized as observational data. Therefore, a logit model was used to identify the factors affecting the farmers' perception of climate change. Moreover, a logit model will guarantee the estimated probability increases and never cross the range of 0 to $1[16]$.

The functional form of logit model was specified which is as follows:

$$
P_{i}=E\left(Y=1 / X_{i}\right)=1 / 1+\mathrm{e}^{-(B o+B i x i)} .
$$

For simplicity Equation (1) was expressed as

$$
P_{i}=1 / 1+\mathrm{e}^{-Z i}
$$

where,

$P_{i}$ is the probability of perception of the farmers the $i^{\text {th }}$ respondent and it ranged from $0-1$. 
$\mathrm{e}^{z i}$ : stands for the irrational number e raised to the power of $Z_{\dot{p}}$

$Z_{\dot{r}}$ is a function of $N$-explanatory variables and expressed as:

$$
Z_{i}=\beta_{0}+\beta_{1} x_{1}+\beta_{2} x_{2}+\cdots+\beta_{n} x_{n}+\mu_{i}
$$

where,

$\beta_{0}$ : is the intercept,

$\beta_{1} \quad \cdots \quad \beta_{n}$ : are slopes of the equation in the model.

Therefore,

$$
\begin{aligned}
Z_{i}= & \beta_{0}+\beta_{1}(E D U)+\beta_{2}(\text { FMLYSZ })+\beta_{3}(\text { FARMSZ }) \\
& +\beta_{4}(\text { FMLYIN })+\beta_{5}(\text { FAREX })+\beta_{6}(\text { CRRE }) \\
& +\beta_{7}(\text { TRRE })+\beta_{8}(\text { COIN })+\beta_{9}(\text { MARAC })+\mu .
\end{aligned}
$$

Prior to the estimation of the logistic regression model the explanatory variable were checked for the existence of multicolinearity. For this purpose, the presence of co-linearity was checked for categorical variables using contingency coefficient test. Therefore, age, number of plots and extension contact were omitted from the logistic model after the multicolinearity test.

\section{Results and Discussion}

\subsection{Characteristics of the Respondents}

The survey results for personal, economic and social characteristics of the respondents are shown in Table 2. The results of the questionnaire found that the farmers in the study were on average 42 years, 39 percent had schooling up to twelfth grade, and 48 percent had a medium sized household of five to six members. Two-thirds of the farmers stated that they had 14 to 26 years of farming experience, and 40 percent said they had received training on agriculture and disaster management prior to the survey. See Table 2 for the descriptive statistics.

The average farm size for the farmers surveyed was 1.57 hectare. This was nearly three times that of the national average farm sized of 0.6 hectare. The average annual income of the farmers' in the study area was BDT 238,201 (\$3043 US), which is more than the national average of BDT 112,240 (\$1403 US) [5]. Arifullah and Haq [17] [18] reported similar pattern of farmers' family income in their study.

The sources of farmers' income stated were mainly crop production, livestock rearing, fish culture and others non-farming activities (e.g. work other than agricultural sector). Non-farming activities include remittances, working at for government organizations and non-governmental organizations and off-farming activities, such as day labor, milling, and post-harvest operations. Shrimp culture proves to be a more profitable enterprise compared to other types of farming in Bangladesh. Since the farms are located in the coastal region (suitable for shrimp culture), this may have been a reason as to why the incomes of the farmers surveyed was nearly doubled the national average.

The majority of the farmers said they had received a line of credit previously and had access to the markets for selling their agricultural products. Just over 
M. N. Uddin et al.

Table 2. Descriptive information for the sample.

\begin{tabular}{|c|c|c|c|c|c|c|c|}
\hline \multirow{2}{*}{ Farmers' characteristics } & \multirow{2}{*}{ Categories of the farmers } & \multirow{2}{*}{$\begin{array}{l}\text { Scoring } \\
\text { method }\end{array}$} & \multirow{2}{*}{$\begin{array}{c}\% \\
\text { respondents }\end{array}$} & \multicolumn{2}{|c|}{ Range } & \multirow{2}{*}{ Mean } & \multirow{2}{*}{$\begin{array}{c}\text { Std. } \\
\text { deviation }\end{array}$} \\
\hline & & & & Min & Max & & \\
\hline \multirow{3}{*}{ Age } & Young (18 - 35) & & 28 & & & & \\
\hline & Meddle aged (36 - 50) & Years & 58 & 28 & 65 & 41.77 & 8.433 \\
\hline & Old aged $(>50)$ & & 14 & & & & \\
\hline \multirow{3}{*}{ Farming experiences } & Low (Up to 13 years) & & 20 & & & & \\
\hline & Medium (14 to 26 years) & Years & 67 & 5 & 45 & 19.44 & 7.811 \\
\hline & High (Above 26 years) & & 13 & & & & \\
\hline \multirow{3}{*}{ Training received } & Training received (1) & & 40 & & & & \\
\hline & & Dummy & 60 & & & & \\
\hline & Not training received $(0)$ & & 60 & & & & \\
\hline \multirow{3}{*}{ Education } & Illiterate $(0)$ & & 27 & & & & \\
\hline & $\begin{array}{l}\text { Primary }(1-5) \\
\text { secondary }(6-12)\end{array}$ & $\begin{array}{c}\text { Years of } \\
\text { schooling }\end{array}$ & $\begin{array}{l}27 \\
39\end{array}$ & 0 & 18 & 6.16 & 4.929 \\
\hline & Higher studies (13 \& above) & & 7 & & & & \\
\hline \multirow{3}{*}{ Family size } & Low (Up to 4$)$ & & 45 & & & & \\
\hline & Medium (5 to 6 ) & Number & 48 & 1 & 13 & 4.93 & 1.827 \\
\hline & High (Above 6) & & 7 & & & & \\
\hline \multirow{4}{*}{ Farm size } & Landless \& Marginal (Up to $0.2 \mathrm{ha}$ ) & & 2 & & & & \\
\hline & Small (0.21 - $1 \mathrm{ha})$ & & 63 & & & & \\
\hline & Medium (1.1 - 3.0 ha) & Hiectare & 25 & 0.10 & 20 & 1.07 & 2.050 \\
\hline & Large (3.1 ha and above) & & 10 & & & & \\
\hline \multirow{3}{*}{ Number of plots } & Low (Up to 5) & & 60 & & & & \\
\hline & Medium (6 - 10) & Number & 28 & 1 & 27 & 6.35 & 5.170 \\
\hline & High (above 10) & & 12 & & & & \\
\hline \multirow{3}{*}{ Family income } & Low Up to $(85000)$ & & 36 & & & & \\
\hline & Medium (85001 - 200000) & $1 \mathrm{BDT}=0.01 \$$ & 41 & 46,600 & 5500,000 & 238,201 & 276,737 \\
\hline & High (above 200000) & & 23 & & & & \\
\hline \multirow{2}{*}{ Credit received } & Credit received (1) & & 75 & & & & \\
\hline & No credit received (0) & D. & 25 & & & & \\
\hline \multirow{2}{*}{ Market access } & Market access (1) & & 76 & & & & \\
\hline & No market access $(0)$ & & 24 & & & & \\
\hline \multirow{2}{*}{ Cooperative involvement } & Involved cooperative (1) & $D_{1}$ & 51 & & & & \\
\hline & Not involved (0) & & 49 & & & & \\
\hline \multirow{3}{*}{ Extension contact } & Low (up to 11) & & 21 & & & & \\
\hline & Medium (12 - 22) & Scale & 42 & 6 & 38 & 19.09 & 8.269 \\
\hline & High (23 and above) & & 37 & & & & \\
\hline
\end{tabular}

Source: Author's field survey. 
half of the farmers of the study area (51\%) stated involvement in cooperatives. The highest proportion of the respondents (79\%) stated medium to high extension services contact, while only $21 \%$ of the respondents reported low contact. These questions were important because farmers require diverse information ranging from soil and water conservations techniques, production procedures, marketing system, sustainable agriculture, environmental sustainability issues that affect the farmers' perception of climate change.

The majority of the farmers surveyed reported being within the ages of 18 to 50 (86\%). Similar findings were found regarding age by Alam; Khan [19] [20]; who reported more than three-fourths of the farmers were in young to middleaged in other locations of Bangladesh that have been researched. The farmers in this study reported that on average completing six years of schooling. Only 27 percent of them reported themselves as illiterate. The literacy rate found in this study was considered relative to the national literacy rate of $61.5 \%$ [21]. Khan [22] found a similar type of literacy rate within the farmers he surveyed. However, other studies reported significant illiteracy rates (73.5\%) of respondents, especially in newly the accreted land (locally known as char land) area of Bangladesh [23]. It is expected that education as one of the crucial factors affecting the farmers' perception of climate change. Additionally, the average families sized of the farmers reported to be 4.93, which is more than national average of 4.50 [24].

On average the farmers reported about 20 years farming experiences of the farmers. This was important to understand that the farmers surveyed have sufficient experience with the changes in climate and weather patterns and the subsequent effects on their decision making and output. It was found that experienced farmers will respond better regarding the climate change events specifically the changing pattern of temperature, rainfall, occurrences of natural hazards such as floods, cyclones, droughts, salinity etc. [25]. Data presented in Table 2 indicate that less than half of the farmers were received training while more than half were not receiving training. Farmers who receive training can employ their skills to tackle various uncertain circumstances.

\subsection{Farmers' Perceptions on Experiencing Climate Change}

The respondents of the study were asked a dichotomous ("yes/no" response) question about whether or not they had experienced changes in the climate of the region within the past 20 years. After their initial response, the farmers were asked about their perceived experience in relation to a series of climatic events commonly associated with global climate change effects in Bangladesh (according to the literature reviewed). They could respond selecting the following; experienced decreases, increases, no change, or they did not know, in the occurrence of the event. Figure 1 reports the responses to the first question. It was found that $88 \%$ of respondents indicated that within the last 20 years they have experienced climatic change events.

Table 3 reports the farmers' response to individual climatic events. Here, all respondents indicated that they had experienced increases in temperature, droughts, 


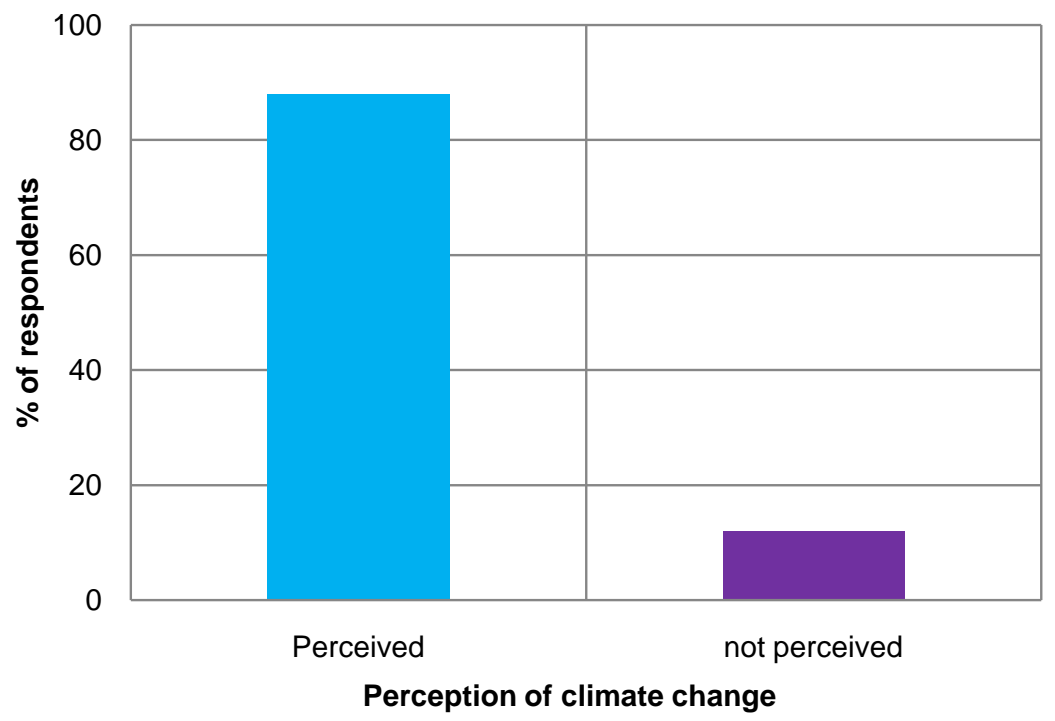

Figure 1. Proportion of respondents by self-reported experience of climatic change.

Table 3. Distribution of responses to perceived changes in specific climatic events $(n=$ $88)$.

\begin{tabular}{lcccc}
\hline \multirow{2}{*}{ Climatic event } & \multicolumn{3}{c}{$\%$ of Respondents } \\
\cline { 2 - 5 } & Increased & No change & Decreased & Don't know \\
\hline Temperature & 100 & 3.4 & 96.6 \\
Rainfall & & & \\
Occurrence of drought & 100 & & \\
Occurrence of flood & 100 & & 10.2 \\
Occurrence of cyclones & 100 & & 5.7 \\
Salinity level & 100 & & \\
Short winter season & 85.2 & 4.6 & 17 \\
Long summer season & 92 & 2.3 & \\
Unpredictable rainfall & 90.9 & 1.1 & \\
Changes of monsoon season & 80.7 & 2.3 & \\
\hline
\end{tabular}

Source: Author's field survey data.

flooding, cyclones, and soil salinity. Across all events, at least $80 \%$ or more reported having experienced climatic shifts which are likely to have a negative impact on agricultural activity. While it is clear that these are perceptions of the farmers surveyed, not calculated events, such information provided important input from the farmers.

The majority of farmers perceived an increased trend of repeated short winter seasons, long summer seasons, unpredicted rainfall and changes of the monsoon season. Increasing temperature along with decreasing precipitation may enhance the water scarcity resulting drought, which, in turn, may affect crop production 
output. These results may also prove vulnerable conditions of the coastal area in Bangladesh due to the climate change effects. The studies conducted by Dhaka et al. [26] found a significant number of farmers believe that temperature was increased while the precipitation was decreased. Besides, similar findings have been reported over the same two decades in these studies in Ethiopia (Legesse et al. 2013), Nigeria (Tambo and Abdoulaye, 2013), and Chile (Roco et al. 2014) [27] [28] [29].

\subsection{Econometric Estimation of Determinants of Farmers' Perception of Climate Change}

The contingency coefficient test was applied before the data analysis to diagnose colinearity and omit independent variables that were highly dependent and strongly correlated to each other, see Table 4. Multi-colinearity was observed between farming experience and age, extension contact and education, the number of plots and farm size, family income and farm size, family income and number of plots, and extension contact and cooperative involvement.

Generally, it is predicted that there should be a positive relationship between family income and farm size. Therefore, both were considered in the logit model reported here, instead of excluding them from the analysis. The model was run with these items omitted and the econometric estimates in those simulations were found to not have significantly changed from the model which maintains family income and farm size. Only age, extension contact, and the number of plots are omitted from the logistic regression model in determining factors affecting the farmers' perception of climate change and shown in Table 5.

The logistic regression model results (Table 5) explain that education is positive and significantly related to the perception of climate change (at 5\% level). This

Table 4. Contingency coefficient test for co-linearity between independent variables.

\begin{tabular}{|c|c|c|c|c|c|c|c|c|c|c|c|c|}
\hline Variables & AG & EDU & FAMSZ & FARSZ & NUMP & FAREX & FAMIN & CRRE & TRRE & COPIN & MARAC & EXCONT \\
\hline AG & 1 & & & & & & & & & & & \\
\hline EDU & -0.046 & 1 & & & & & & & & & & \\
\hline FAMSZ & 0.368 & 0.114 & 1 & & & & & & & & & \\
\hline FARSZ & 0.213 & $0.393^{*}$ & $0.354^{*}$ & 1 & & & & & & & & \\
\hline NUMP & 0.181 & $0.35^{*}$ & $0.382^{*}$ & $0.853^{* *}$ & 1 & & & & & & & \\
\hline FAREX & $0.887^{\star *}$ & -0.114 & $0.360^{*}$ & 0.163 & 0.162 & 1 & & & & & & \\
\hline FAMIN & 0.195 & $0.344^{*}$ & 0.229 & $0.893^{* *}$ & $0.639^{* *}$ & 0.131 & 1 & & & & & \\
\hline CRRE & 0.223 & 0.113 & 0.117 & 0.202 & 0.254 & 0.178 & 0.139 & 1 & & & & \\
\hline TRRE & 0.095 & 0.331 & 0.143 & $0.344^{*}$ & $0.341^{*}$ & 0.009 & 0.245 & $0.363^{*}$ & 1 & & & \\
\hline COPIN & 0.048 & $0.506^{*}$ & 0.158 & $0.347^{*}$ & $0.36^{*}$ & -0.040 & 0.237 & 0.242 & $0.343^{*}$ & 1 & & \\
\hline MARAC & 0.054 & $0.495^{*}$ & 0.171 & 0.236 & 0.288 & 0.034 & 0.166 & 0.270 & 0.188 & $0.410^{*} 1$ & & \\
\hline EXCONT & 0.032 & $0.756^{\star *}$ & 0.164 & $0.457^{*}$ & $0.446^{*}$ & 0.018 & $0.391^{*}$ & 0.155 & $0.355^{*}$ & $0.526^{\star *}$ & $0.398^{\star}$ & 1 \\
\hline
\end{tabular}

${ }^{\star}$ Weak co-linearity between the two variables; ${ }^{* *}$ High co-linearity between the two variables. 
Table 5. Estimates of binary logit regression model based on farmers' perception of climate change.

\begin{tabular}{cccc}
\hline & & Perception & \\
\cline { 2 - 4 } Variables & Coefficient & Robust Std. Error & P Value \\
\hline CONS & 0.1051 & 4.1100 & 0.693 \\
EDU & $0.6520^{* *}$ & 0.30585 & 0.033 \\
FAMSZ & $-0.6830^{*}$ & 0.3794 & 0.072 \\
FARSZ & $-3.1210^{* *}$ & 1.6065 & 0.052 \\
FAMIN & $0.0001^{* *}$ & 0.0000 & 0.031 \\
FAREX & $2.3668^{*}$ & 1.3947 & 0.120 \\
CRRE & -1.354 & 2.1237 & 0.512 \\
TRRE & $6.861^{*}$ & 4.3280 & 0.091 \\
COIN & 6.929 & 3.9734 & 0.112 \\
MARACC & 0.0913 & 2.092 & 0.789 \\
R & & 0.786 & \\
\hline
\end{tabular}

**, *indicate significant level at $5 \%$ and $10 \%$ respectively.

implies that the probability of perception of climate change is greater for those who have higher educational attainment compared to less-educated or illiterate farmers. It is apparent that educated farmers have more knowledge, ability to understand and respond to expected changes, able to forecast future scenarios and have greater access to information and opportunities than others. These issues lead to the farmers who perceive more about climate change. Education as an influencing factor of farmers perception of climate change was also found in studies conducted by other researchers [30] [31] [32] [33].

Family size was negative and significant (at the $10 \%$ level) when related to farmers' perception of climate change. However, the negative sign on this relationship was contradictory to what the researchers would have thought. These findings indicated that with increasing size of the family, the probability of farmers' perception of climate change decreased. Prior to this study, it was expected that the sign of the variable family size would have a positive, the logic being that large family size makes more interaction among the family members, which increases the perception of climate change. Moreover, the results indicated that larger family size had less probability of perceiving of climate change than smaller family size. It is may be the larger family numbers interact less with each other, have less access to extension contact, are unable to attend training programs, and/or rather act as labor forces. Similar findings have found in other studies [34] [35] [36].

There was a negative and significant (at the 5\% level) relationship between farm size and perception of climate change. Specifically, results show that the larger the size of a farm operation decreased the probability of farmers' perceiving climate change. Larger farms require greater levels of investment and production inputs 
such as seeds, fertilizer, pesticides, irrigation facilities, which are stressors on farm budgets. To utilize these inputs require more education, experience and managerial capacity which may influence the farmers' perception of climate change. The potential explanation may be that all farmers have the potentiality but may be lack of proper education, training, poor communication exposures and fail to perceive more. The similar results revealed studies conducted by the others [37] [38].

The result of the logic model shows that positive and significant (at the 5\% level) relationship between family income and farmers' perception of climate change effects. This implies that farmers with high income are more likely to have the more access to resources than farmers with lower incomes, which include trainings about the effects of climate change. The Government Organizations (GOs) and Non-Government Organizations (NGOs) have programs designed to create off-farm livelihoods activities which result in increased income and continued agricultural operations in the face of climatic uncertainty. Other sources of off-farm income, such as remittances and off-farm jobs might influence to farmers' perception. Semenza et al. (2008) [38] found that household income positively and significantly influenced the perception of climate change while Akanda and Howlader (2015) [33] explained that family income was a great influence to farmers' perception of climate change.

Farming experience was found positive and significant (at the 5\% level) relationship with farmers' perception of climate change, as confirmed by the logistic regression model. Experienced farmers were more aware in changing temperature, rainfall, and other disaster events. These experiences might be helpful to understand the prediction of future changes of these events and have been identified in other research [12] [37] [39].

The results show that positive and significant (at the $10 \%$ level) relationship between training received and farmers' perception of climate change. Any inclusion of training reported by the interviewed farmers helped them to identify climate change events, and can help the farmers more adept at handling tasks to prepare for climate change event. Similar results found by the conduction of another researcher with regards to cocoa farming and farmers' perception on climate variability [40].

\section{Conclusion and Recommendations}

The findings from this study revealed that the majority (88\%) of the farmers in the study area perceived changes in climatic conditions, whereas only $12 \%$ did not. Almost all farmers reported increases in temperature, droughts, floods, cyclones, salinity level and decreasing the rainfall over the last 20 years. Increasing temperature along with decreasing precipitation may enhance the water scarcity from resulting droughts which will affect crop production. The logit model explained that out of the nine factors surveyed; education, family size, farm size, family income, farming experiences, and training received, were found to be significantly related to the farmers' perception of climate change and indentified as 
influential factors of farmers' perception of climate change. Respective authorities, especially government and non-government organizations, should create policy measures that consider these influential factors of farmers' perception of climate change. This, in turn, may have a significant contribution to farmers' reducing the risks that they lose against climate change effects. The policy measures may be focused on capacity building of the farmers, institutional supports, easy way-out of receiving support from the concern authorities, ensuring the accountability of the supportive staff who have been working with farmers intensively.

\section{Acknowledgements}

The authors are acknowledged to the farmers from the study area for their contributions, Professor Dr. Md. Abdul Momen Miah, Professor Dr. M. Asaduzzaman Sarker and Mr. Maruf Billah (BAU, Mymensingh, Bangladesh) for their kind cooperation about data collection of this study. The paper was based on the first author's graduate study at Humboldt University of Berlin (HUB), Germany under Erasmus Mundus Scholarship funded by European Commission (EC).

\section{Author Contributions}

Mohammed Nasir Uddin is the primary author. He designed the field study, implemented data collection, and selected and implemented the analytical methodology. The work presented here is an extension of that completed for his master thesis, successfully defended for the International Master of Rural Development with its Secretariat at Universiteit Ghent, Belgium.

Wolfgang Bokelmann was the faculty advisor and thesis promoter of Mohammed Nasir Uddin. He contributed to the project inception, selection of the methodological framework, and writing of the thesis document upon which this article was based in an advisory capacity.

Emily S. Dunn edited and contributed to the style, contents and overall flow of the paper. She is an Instructor in the Department of Agribusiness within the College of Food and Agriculture in the United Arab Emirates University.

\section{Conflicts of Interest}

The authors declare no conflict of interest.

\section{References}

[1] Younus, M.A.F. and Harvey, N. (2014) Economic Consequences of Failed Autonomous Adaptation to Extreme Floods: A Case Study from Bangladesh. Local Econo$m y, 29,22-37$. https://doi.org/10.1177/0269094213515175

[2] Molla, I.H. (2016) Environment and Climate Change in Bangladesh: Challenges and the Role of Public Administration. Resources and Environment, 6, 1-8.

[3] National Adaptation Programme of Action (NAPA) (2005) Final Report: Ministry of Environment and Forest, Government of the People's Republic of Bangladesh (GOB), Dhaka, 48.

[4] Lázár, A.N., Clarke, D., Adams, H., Akanda, A.R., Szabo, S., Nicholls, R.J., Matthews, Z., Begum, D., Saleh, A.F.M., Abedin, M.A., Payo, A., Streatfield, P.K., Hut- 
ton, C., Mondal, M.S. and Moslehuddin, A.Z.M. (2015) Agricultural Livelihoods in Coastal Bangladesh under Climate and Environmental Change-A Model Framework. Environmental Science: Processes \& Impacts, 17, 1018-1031. https://doi.org/10.1039/C4EM00600C

[5] Uddin, M.M.M. (2015) Causal Relationship between Agriculture, Industry and Services Sector for GDP Growth in Bangladesh: An Econometric Investigation. Journal of Poverty, Investment and Development, 8, 124-129.

[6] Van den Ban, A.W. and Hawkins, H.S. (2000) Agricultural Extension. 2nd Edition, Blackwell Science, UK.

[7] Saarinen, T.F. (1976) Environmental Planning: Perception and Behavior. Houghton Mifflin Company, Boston.

[8] Khan, M.R.U., Azad, A.K. and Nusrat, J. (2012) Farmers' Perception on Climate Variability. Lambert Academic Publishing, Saarbrücken.

[9] Haque, M.A., Yamamoto, S.S., Malik, A.A. and Sauerborn, R. (2012) Households' Perception of Climate Change and Human Health Risks: A Community Perspective. Environmental Health, 11, 1. http://www.ehjournal.net/content/11/1/1 https://doi.org/10.1186/1476-069X-11-1

[10] Nyanga, P.H., Johnsen, F.H., Aune, J.B. and Kalinda, T.H. (2011) Smallholder Farmers' Perceptions of Climate Change and Conservation Agriculture: Evidence from Zambia. Journal of Sustainable Development, 4, 73. https://doi.org/10.5539/jsd.v4n4p73

[11] Maddison, D. (2007) The Perception of and Adaptation to Climate Change in Africa. Policy Working Paper.

[12] Gbetibouo, G.A. (2009) Understanding Farmers' Perceptions and Adaptations to Climate Change and Variability: The Case of the Limpopo Basin, South Africa. IFPRI Discussion Paper, 36.

[13] Tiwari, K., Awasthi, K., Balla, M. and Sitaula, B. (2010) Local People's Perception on Climate Change, Its Impact and Adaptation Practices in Himalaya to Terai Regions of Nepal. Himalayan Research Papers Archives, Nepal Study Center, University of New Mexico.

[14] Gujarati, D.N. (1995) Basic Econometrics. 4th Edition, United State Military Academy, New York.

[15] Rahm, M.R. and Huffman, W.E. (1984) The Adoption of Reduced Tillage: The Role of Human Capital and Other Variables. American Journal of Agricultural Economics, 66,405-413. https://doi.org/10.2307/1240918

[16] Uddin, M.N., Bokelmann, W. and Entsminger, J.S. (2014) Factors Affecting Farmers' Adaptation Strategies to Environmental Degradation and Climate Change Effects: A Farm Level Study in Bangladesh. Climate, 2, 223-241. https://doi.org/10.3390/cli2040223

[17] Arifullah, M., Zahan, A., Rana, M.M., Adil, M. and Shamsunnaher, S. (2014) Attitude of the Rural Elite Farmers towards Extension Activities Performed by Personnel of Department of Agricultural Extension. The Agriculturists, 12, 96-102. https://doi.org/10.3329/agric.v12i1.19586

[18] Haq, A.Z.M. (2016) Agricultural Extension Contact and Farmer's Income in Bangladesh. Turkish Journal of Agriculture-Food Science and Technology, 4, 787-792.

[19] Alam, M.O. and Rashid, M.U. (2010) Problem Confrontation of Costal Youth in Undertaking Selected Agricultural Activities in Two Village under Bhola District. Bangladesh Research Publication Journal, 4, 165-171.

[20] Khan, J.H. and Naz, N. (2016) Pattern of Commuting: A Case Study in Aligarh City. 
International Journal of Humanities and Applied Social Science, 1, 55-68.

[21] Khatun, N. and Miwa, J. (2016) An Autonomous Learning System of Bengali Characters Using Web-Based Intelligent Handwriting Recognition. Journal of Education and Learning, 5, 122-138. https://doi.org/10.5539/jel.v5n3p122

[22] Khan, A.R. (2015) Domestic Violence against Women in Bangladesh: A Review of the Literature and the Gaps to Fill-In by Future Intervention. Khazar Journal of Humanities and Social Sciences, 18, 57-80.

[23] Rahman, S. and Davis, J. (2005) A Survey of Rural Livelihood and Enterprise Development Opportunities in the Chars, Bangladesh: DFID Poverty Oriented Research Programme R8369 (NRI: C1731).

[24] Household Income and Expenditure Survey (HIES) (2010) Bangladesh Bureau of Statistic. Ministry of Planning, Government of People's Republic of Bangladesh. Dhaka, 23.

[25] Uddin, M.N. (2012) An Analysis of Farmers' Perception and Adaptation Strategies of Climate Change in Bangladesh. Master's Thesis, Humboldt University of Berlin, Berlin.

[26] Dhaka, B.L., Chayal, K. and Poonia, M.K. (2010) Analysis of Farmers' Perception and Adaptation Strategies to Climate Change. Libyan Agriculture Research Center. Journal International, 1, 388-390.

[27] Legesse, B., Ayele, Y. and Bewket, W. (2013) Smallholder Farmers' Perceptions and Adaptation to Climate Variability and Climate Change in Doba District, West Hararghe, Ethiopia. Asian Journal of Empirical Research, 3, 251-265.

[28] Tambo, J. and Abdoulaye, T. (2013) Smallholder Farmers' Perceptions of and Adaptations to Climate Change in the Nigerian Savanna. Regional Environmental Change, 13, 375-388. https://doi.org/10.1007/s10113-012-0351-0

[29] Roco, L., Engler, A., Bravo-Ureta, B. and Jara-Rojas, R. (2014) Farmers' Perception of Climate Change in Mediterranean Chile. Regional Environmental Change, 15, 113.

[30] Mustapha, S.B., Sanda, A.H. and Shehu, H. (2012) Farmers' Perception of Climate Change in Central Agricultural Zone of Borno State, Nigeria. Journal of Environment and Earth Science, 2, 21-28.

[31] Ndambiri, K., Ritho, C., Mbogoh, G., Ng'ang'a, I., Muiruri, J., Nyangweso, M., Kipsat, J., Omboto, I., Ogada, O., Kefa, C., Kubowon, C. and Cherotwo, H. (2012) Analysis of Farmers' Perceptions of the Effects of Climate Change in Kenya: The Case of Kyuso District. Journal of Environment and Earth Science, 2, 74-83.

[32] Amdu, B., Ayehu, A. and Deressa, A. (2013) Farmers' Perception and Adaptive Capacity to Climate Change and Variability in the Upper Catchment of Blue Nile, Ethiopia. The African Technology Policy Studies Network (ATPS), Nairobi.

[33] Akanda, M.G.R. and Howlader, M.S. (2015) Farmers' Perception of Climate Change Effects on Agriculture at Galachipa Upazila under Patuakhali District of Bangladesh. Global Journal of Science Frontier Research, 15, 31-39.

[34] Falaki, A.A., Akangbe, J.A. and Ayinde, O.E. (2013) Analysis of Climate Change and Rural Farmers' Perception in North Central Nigeria. Journal of Human Ecology, 43, 133-140.

[35] Ndambiri, K., Ritho, C. and Mbogoh, G. (2013) An Evaluation of Farmers' Perceptions of and Adaptation to the Effects of Climate Change in Kenya. International Journal of Food and Agricultural Economics, 1, 75-96.

[36] Oluwatusin, F.M. (2014) The Perception of and Adaptation to Climate Change among Cocoa Farm Households in Ondo State, Nigeria. Academic Journal of Inter- 
disciplinary Studies, 3, 147-156.

[37] Sanog, K., Binam, J., Bayala, J., Villamor, G.B., Kalinganire, A. and Dodiomon, S. (2012) Farmers' Perceptions of Climate Change Impacts on Ecosystem Services Delivery of Parklands in Southern Mali. Agroforestry Systems, 1-17.

[38] Semenza, J.C., Hall, D.E., Wilson, D.J., Bontempo, B.D., Sailor, D.J. and George, L.A. (2008) Public Perception of Climate Change Voluntary Mitigation and Barriers to Behaviour Change. American Journal of Preventive Medicine, 35, 479-487. https://doi.org/10.1016/j.amepre.2008.08.020

[39] Montle, B.P. and Teweldemedhin, M.Y. (2014) Assessment of Farmers' Perceptions and the Economic Impact of Climate Change in Namibia: Case Study on SmallScale Irrigation Farmers (SSIFs) of Ndonga Linena Irrigation Project. Journal of Development and Agricultural Economics, 6, 443-454. https://doi.org/10.5897/JDAE2014.0596

[40] Ehiakpor, D.S., Danso-Abbeam, G. and Baah, J.E. (2016) Cocoa Farmer's Perception on Climate Variability and Its Effects on Adaptation Strategies in the Suaman District of Western Region, Ghana. Cogent Food \& Agriculture, 2, Article ID: 1210557. https://doi.org/10.1080/23311932.2016.1210557

Submit or recommend next manuscript to SCIRP and we will provide best service for you:

Accepting pre-submission inquiries through Email, Facebook, LinkedIn, Twitter, etc. A wide selection of journals (inclusive of 9 subjects, more than 200 journals)

Providing 24-hour high-quality service

User-friendly online submission system

Fair and swift peer-review system

Efficient typesetting and proofreading procedure

Display of the result of downloads and visits, as well as the number of cited articles

Maximum dissemination of your research work

Submit your manuscript at: http://papersubmission.scirp.org/

Or contact ajcc@scirp.org 